\title{
CIENCIA, VALORES Y POLÍTICA EN LOS CLÁSICOS DE LA SOCIOLOGÍA
}

\section{SCIENCE, VALUES AND POLITICS IN THE CLASSICAL THEORISTS IN SOCIOLOGY}

\section{Celia Duek*}

\author{
RESUMEN
}

¿Cuál es la relación de la ciencia con la política, por un lado, y de la ciencia con la moral o los valores, por otro? ¿El pensamiento teórico es independiente del pensamiento político de un autor? ¿Es posible una ciencia social neutral? ¿Es lícita la búsqueda de objetividad en la Sociología? ¿Puede la ciencia decirnos qué hacer o cómo organizarnos? En la producción intelectual de los tres clásicos de la Sociología, se encuentran respuestas disímiles a estas preguntas. Este artículo aborda comparativamente sus miradas acerca de estos problemas, partiendo de la consideración weberiana, para luego compararla con la de Durkheim y Marx.

PALABRAS CLAVE: FILOSOFÍA DE LA CIENCIA * SOCIOLOGÍA * CIENCIA Y SOCIEDAD * EPISTEMOLOGÍA

\section{ABSTRACT}

What is the relationship of science with politics, on the one hand, and science with morals or values, on the other? Is theoretical thinking independent of the political thought of an author? Is a neutral social science possible? Is the search for objectivity in sociology lawful? Can science tell us what to do or how to organize? In the intellectual production of the three classical theorists in sociology we find dissimilar answers to these questions. This article compares the views on these problems, starting with the weberian consideration, and then comparing it with Durkheim and Marx.

KEYWORDS: SCIENCE PHILOSOPHY * SOCIOLOGY * SCIENCE AND SOCIETY * EPISTEMOLOGY 


\section{INTRODUCCIÓN}

En el 2017, se cumplieron 100 años de la conferencia de Max Weber "La ciencia como vocación". En ocasión de ello, el equipo de la cátedra "Pensamiento de Max Weber" de la Facultad de Ciencias Sociales de la Universidad de Buenos Aires convocó a algunos colegas para participar de un panel ${ }^{1}$ (incluyendo a la autora) en el que se reflexionó sobre el texto. Introduciendo varias modificaciones y precisiones, en estas páginas se rescata y amplía las ideas que se desarrollaron en dicha oportunidad.

El propósito fundamental de este trabajo es dar cuenta del modo en que concibe Weber la relación de la ciencia social con la esfera de los valores; su distinción entre las tareas de la ciencia y las de la política, y la lógica específica de cada uno de estos ámbitos; para luego compararlo y contraponerlo con la perspectiva de los otros dos clásicos de la Sociología: Emile Durkheim y Karl Marx.

Se señala en primer lugar, dónde se ubica la conferencia "La ciencia como vocación", dictada por Weber en 1917, en relación al conjunto de la producción del sociólogo alemán. Retomando la división que Raymond Aron (1970) hace de sus trabajos en cuatro categorías: 1) metodológicos o filosóficos, 2) históricos, 3) trabajos de Sociología de la religión y por último, 4) de Sociología general. Las ideas de este trabajo pueden situarse sin duda alguna en la primera de las categorías, es decir, en el contexto de las preocupaciones epistemológicas, metodológicas o de filosofía de la ciencia de Weber.

\section{CIENCIA, VALORES Y POLIITICA DESDE LA PERSPECTIVA WEBERIANA}

La conferencia de 1917 tiene dos ejes. Uno atañe a cuestiones de la ciencia para quien la ejerce como profesión, en este sentido, Weber

1 El panel se denominó "Max Weber: Cultura y sociedad. A 100 años de La ciencia como vocación/profesión". Tuvo lugar en las XII Jornadas de Sociología de la Universidad de Buenos Aires, en agosto de 2017, y participaron también como panelistas Eduardo Rinesi y Marcelo Urresti. se ocupa de la carrera científica o el sistema universitario en Alemania y en Estados Unidos, de los requisitos para su ejercicio, de las exigencias de investigación y docencia como cualidades que no necesariamente coinciden en la misma persona, de los mecanismos de selección de profesores, etc.

El otro eje es el valor de la ciencia en sí, frente a la vida humana, $y$ dentro de esto, específicamente, la relación de la ciencia con los valores, tema en el que se centra este documento. Esta preocupación no es exclusiva de este texto sino que es una preocupación repetida de Weber, que se podría decir que inicia en textos muy anteriores ("La 'objetividad' cognoscitiva de la ciencia social y la política social", "Estudios críticos sobre la lógica de las ciencias de la cultura", "Introducción metodológica a las encuestas de la Asociación de Política Social sobre selección y adaptación de los obreros en las grandes fábricas") y se extiende en esta última y tercera etapa ("El sentido de la "neutralidad valorativa' de las ciencias económicas y sociológicas", "La ciencia como vocación").

Tener en cuenta la distinción que hace Weber entre "juicios de valor" y "relación de valor" es importante para comprender cómo piensa esa relación de la ciencia con los valores, del conocimiento de lo fáctico con lo valorativo. La incomprensión de esa diferencia ha dado lugar, desde nuestro punto de vista, a interpretaciones equívocas de la postura del fundador de la sociología comprensiva.

Para Weber (1990a, 1990b, 1990c, 1994) una cosa son las tomas de posición concretas frente a la deseabilidad o no de determinados fenómenos, a su carácter positivo o negativo, satisfactorio o no, desde puntos de vista éticos, morales, políticos, etc., a lo que llama "juicios de valor", que deben evitarse en el discurso científico; $y$ otra cosa es el condicionamiento de la ciencia por puntos de partida extracientíficos, valorativos (ideales o valores últimos que condicionan el recorte, la selección o la formación del objeto de investigación, problema, aspectos, etc.). Aunque reconoce para las ciencias de la cultura esta "relación con los valores" en su determinación del interés cognitivo, rechaza fuertemente la posibilidad de una ciencia ética 
o de la introducción de argumentos dirigidos a la conciencia (el deber ser) en el desarrollo de la investigación científica.

Como bien lo señala, Jorge Rovira (2004) hace varios años en esta misma revista en su análisis minucioso del abordaje weberiano de la relación entre ciencias sociales $y$ valores:

...para Weber este proceder irreductiblemente subjetivo que es la relación con los valores, preámbulo del proceso de inquisición científica entendido más estrictamente, en modo alguno atenta contra la objetividad a la que aspira la ciencia social, ni, en consecuencia, a la obtención de verdades intersubjetivas 0 , si se prefiere, al logro de afirmaciones sobre la realidad cuya verdad o falsedad pueden ser establecidas de manera convincente $y$ satisfactoria (p. 131).

La postulación de la objetividad o neutralidad axiológica de las ciencias sociales se repite en diversos textos/momentos a lo largo de la obra de Weber. Pero en "La ciencia como vocación” esa relación ciencia/valores está formulada en términos de los límites de la ciencia en el contexto del desencantamiento del mundo (esto podría ser una particularidad de este trabajo de 1917).

Una de las tesis centrales del texto es que la ciencia y la técnica han llevado adelante un proceso de racionalización, intelectualización $y$ a la vez, desencantamiento del mundo (o desmagificación), que significa que todo puede ser dominado mediante el cálculo y los medios técnicos, que no hay poderes secretos e imponderables, que no es necesario recurrir a la magia para aplacar espíritus o solicitar algo de ellos (Weber, 1983).

Esto no significa —explica Weber-que el hombre común sepa más sobre las condiciones que lo rodean que el indio o el salvaje (este conoce sus herramientas, sabe cómo conseguir alimento, etc.). Como ciudadanos corrientes, no sabemos ni necesitamos saber cómo funciona el tranvía (y lo mismo se podría decir hoy de un avión, un celular, una computadora), pero si se quisiera se podría saber porque la sociedad lo sabe a través del personal científico y técnico.
Pues bien, la ciencia es miembro y fuerza motriz de este progreso en la cultura occidental. Pero a la vez que permite ese dominio — razona-, la ciencia tiene sus límites, y esos límites los encuentra en el terreno de lo valorativo. La ciencia enseña cómo dominar la vida mediante la técnica; da métodos de pensamiento ( $y$ da la forma para desarrollarlos) y aporta claridad; ayuda al individuo a conocer el sentido último de sus actos: cuáles son sus fines, cuáles las posibles consecuencias secundarias, qué medios para tal fin, etc. (Weber, 1983), en cambio, no nos puede decir qué hacer o cómo vivir.

Este es el planteamiento central de la conferencia. El saber científico no muestra el comportamiento ético adecuado, el camino hacia el verdadero arte, hacia dios, el sentido del mundo, el camino hacia la felicidad (todas ilusiones del pasado). Eso en todo caso es propio del discurso religioso, $y$ la ciencia es ajena a lo divino. Para Weber, no hay cabida para una ciencia social ética, para una ciencia ética de la economía, por ejemplo. La ciencia no puede dar como resultado una ética capaz de decir lo que debe valer.

Sucede que Weber, aunque de ninguna manera es una figura apolítica o desinteresada de la política (incluso se habla de la profunda tensión interior entre su pasión científica y su pasión política), establece una separación de principio entre ciencia y política, así como entre ciencia y moral. La ciencia y la política tienen lógicas, éticas y reglas muy distintas.

Weber se afana por distinguir las tareas de la ciencia de las de la política; las de la ciencia social, de las de la política social. Si la primera busca acceder a verdades empíricamente demostrables, de validez objetiva, la segunda es afirmación y adhesión a determinados ideales, siempre subjetivos. Según el texto metodológico de 1904, "La 'objetividad' cognoscitiva de la ciencia social y de la política social", la exposición de los ideales atañe a la "política social", mientras que la "ciencia social" es el "ordenamiento conceptual" de los hechos (Weber, 1990c, p. 49).

En una época como la actual, donde se ha acuñado el término posverdad, donde para algunos no es relevante si las afirmaciones 
son verdaderas o falsas, donde se recurre a las emociones $y$ creencias desdeñando los hechos objetivos (donde un gobierno o unos medios de comunicación pueden decir que hay crecimiento económico, que baja la inflación, que se actúa para disminuir la pobreza, aun cuando toda la evidencia vaya en sentido contrario), la apelación de Weber a la búsqueda de la verdad como tarea de la ciencia retoma actualidad, o al menos incita a la reflexión. Desde el punto de vista de la población científica, cuya lógica es la de intentar demostrar (teórica o empíricamente) los argumentos o aseveraciones, la generalización de prácticas que se identifican con esta noción de posverdad (expresión incluida en el diccionario de la Real Academia Española a fines de 2017) donde no importa la validación de los dichos, es motivo de preocupación. Weber menciona en este texto la "comprobación de los hechos", indispensable a la ciencia.

Tanto en "El sentido de la "neutralidad valorativa' de las ciencias económicas y sociológicas" (1990a), como en "La 'objetividad' cognoscitiva de la ciencia social y la política social" (1990c), Weber condena inequívocamente la introducción de "valoraciones" políticas o éticas, de censura o aprobación, en la investigación científica y en la enseñanza académica. Para Weber, una acción que genera molestia es que docentes expongan en las aulas concepciones del mundo "en nombre de la ciencia" o como si fueran verdades objetivas. Lo mismo ocurre en "La ciencia como vocación", donde explica que en el análisis científico no hay cabida para la opinión práctico-política, y condena el uso de la autoridad o posición privilegiada de algunos maestros y algunas maestras en el aula (pues son quienes hablan y el alumnado calla) para imponer sus propios puntos de vista o sus conceptos personales (1983, pp. 40-41). De modo que reitera el postulado de la "neutralidad de valores" y de la necesidad de "neutralizar nuestras simpatías" y "conceptos políticos personales" en el trabajo docente o de investigación.

Por eso Weber hace la distinción entre maestro o erudito, por un lado, y profeta, demagogo o líder político, por otro, que orientan en la vida, en las concepciones del mundo. Si el profesor quiere ser un líder o mentor de la juventud, debe hacerlo fuera del aula, en las reuniones políticas (a donde la adhesión clara a un punto de vista es un deber, $y$ las palabras son armas para la lucha), en los medios de prensa, etc.

Puede que los posicionamientos valorativos no sean evitables, por ejemplo, en la docencia es un mandato de honestidad intelectual que el profesorado advierta ante su alumnado $y$ ante sí mismo cuáles de sus aseveraciones corresponden a hechos deducidos lógicamente u observados empíricamente, y cuáles a valoraciones prácticas (Weber, 1990a).

El terreno de los valores (políticos, éticos, religiosos) es —argumenta Weber-el de una lucha inextricable. Los distintos sistemas de valor se encuentran en lucha (lucha entre distintos dioses), en una lucha que dura por toda la eternidad, pues las posturas definitivas son incompatibles, $y$ la ciencia no tiene la capacidad de decidir entre esos sistemas y resolver el conflicto (1983). La ciencia puede interpretar una ética, no afirmarla o refutarla.

Cada individuo tiene sus dioses y demonios, y está solo ante la decisión de qué es dios y qué es demonio para él, solo él puede escoger entre dos sistemas de valor (1983). Como dice Raymond Aron en su interpretación de este gran clásico de la Sociología: "no hay una tabla científica de valores" (1970, p. 299).

La ciencia no puede ayudar, y por otro lado, con el debilitamiento de la religión, se vive en una época "sin dioses ni profetas"; es decir, la ciencia desplazó a la religión y el ser humano queda más librado a sus propias elecciones, más solo, en el campo de las cuestiones de conciencia u opciones morales: “...Los valores más sublimes y supremos han desaparecido del dominio público, ocultándose ya sea en el reino trasmundano de la vida mística, ya sea en las relaciones fraternales entre los individuos" (Weber, 1983, p. 57). En consecuencia, las opciones éticas pertenecen cada vez más al ámbito de lo privado, dejan de tener un carácter general y obligatorio: la racionalización, la intelectualización y el desencantamiento son el destino de nuestra época.

Ese tipo de reflexiones es el que que conducen al profesor weberiano Julien Freund a 
establecer una contraposición entre "Sociología científica" y "Sociología reformadora", encontrando en Max Weber un representante de la primera y en Marx, Comte o Spencer exponentes de la segunda. Según Freund (1986), la Sociología de Weber:

... supuso un verdadero giro en la historia de esta disciplina, que se convierte en una ciencia positiva y empírica. A pesar de las protestas de fidelidad al espíritu científico [...] las diversas sociologías del siglo XIX fueron mucho más doctrinales que científicas... Tenían, ante todo, la pretensión de modificar la sociedad existente. Más exactamente, estas sociologías eran más reformas que ciencia. El análisis del ser y de la realidad sólo suponía un pretexto que debía aprovechar el deber-ser $y$ servir los planes de la transformación social (pp. 14-15).

En efecto, una de las críticas de Weber al marxismo se dirige, entre otras cosas, a su "falta de neutralidad", a su carácter "dogmático", o a lo que él considera una concepción "normativa" de la historia, ya sea porque toma partido a favor de la clase obrera, o profetiza sobre la inevitable ruina del capitalismo o porque postula la necesidad de la revolución socialista. De este modo, la concepción materialista de la historia, establece preceptos para la acción, cuando a juicio de Weber: “... jamás puede ser tarea de una ciencia empírica proporcionar normas e ideales obligatorios, de los que puedan derivarse preceptos para la práctica" (1990c, p. 41). Como lo expresa Raymond Aron (1970):

La sociología de Weber... propone una doble negación: Ninguna ciencia podrá indicar a los hombres cómo deben vivir o enseñar a las sociedades cómo deben organizarse. Ninguna ciencia podrá indicar a la humanidad la naturaleza de su futuro. La primera negación lo opone a Durkheim, la segunda a Marx (pp. 250-251).

Para la filosofía weberiana, la ciencia no puede anticipar la naturaleza del futuro - añade Aron- porque este no se encuentra predeterminado y en todo caso, el individuo es libre de rechazar ese determinismo parcial o de adaptarse a él de diferentes modos. En síntesis, para Weber la ciencia no da un conocimiento del deber ni del destino (Aron, 1998).

\section{COMPARACIÓN CON DURKHEIM Y MARX: CIENCIA, MORAL Y POLÍTICA EN OTROS CLÁSICOS DE LA SOCIOLOGÍA}

Si se presta atención en las razones por las que Aron dice que esto lo opone a Durkheim y a Marx, la comparación es interesante, ya que se trata de los tres clásicos de la Sociología ¿Cómo entendía Durkheim las relaciones entre ciencia y política, $y$ entre ciencia $y$ moral? En primer lugar hay que señalar que su concepción del papel del profesor lo ponía al margen de todo compromiso político directo (partidario), y de los tres clásicos fue el que estuvo implicado en menor medida a nivel personal en los grandes acontecimientos políticos de su época: casi todas sus obras tienen un carácter puramente académico.

Como bien lo explica el especialista Lukes (1984), Durkheim creía que aunque los investigadores tenían el deber de participar en la vida pública, la actividad política cotidiana en partidos y en el Parlamento, esta participación era dañina para la labor académica. Los intelectuales debían ser consejeros y educadores: su influencia debía darse a través de las clases, los libros y la educación popular. El fundador de la Sociología francesa desconfiaba de la política vulgar como juego superficial de partidos y personalidades, por ello creía que el académico debía abstenerse de tomar parte en campañas $y$ asuntos políticos, excepto que se debatieran grandes cuestiones sociales y que estuvieran amenazados los ideales de la república.

En Las reglas del método sociológico, Durkheim (1984) concluye que la Sociología no debe tomar partido. No será individualista ni comunista ni socialista. Ignorará estas teorías que tienden no a expresar los hechos sino a reformarlos. Sin embargo, él trató siempre de usar el faro del conocimiento sociológico para arrojar luz sobre cuestiones prácticas, para resolver problemas políticos y sociales (reorganización 
del sistema educativo, formación de funcionarios, laicisimo, divorcio, etc.).

Esta última cuestión es la que justifica la oposición que establece Aron entre Durkheim y Weber. El pensador francés, para decirlo de modo sencillo, es más optimista que Weber respecto del papel que corresponde a la ciencia. Se podría decir que se acerca más a la idea de la "omnipotencia" de la ciencia.

Según Durkheim, hay quienes piensan que la ciencia conoce hechos, los observa, los explica, pero no los juzga, pues para esta no existiría el bien y el mal, no habría hechos censurables, nada puede enseñar acerca de lo que se debe querer. Él se distancia de esa postura pues entiende que "...prácticamente se despoja a la ciencia de toda eficacia práctica, y por lo tanto no se le reconoce mayor razón de ser; pues ¿para qué nos esforzamos por alcanzar el conocimiento de lo real, si no puede servirnos en la vida?" (1984, p. 69).

Desde su perspectiva, los "valores morales sí se pueden determinar por la ciencia": esta enseña cuáles son las ideas morales más adecuadas a las nuevas condiciones industriales. A diferencia de Weber, Durkheim buscó construir una sociología con una función práctico-política: proporcionar los preceptos "morales" para el afianzamiento de la unidad nacional, en la III República Francesa.

Si la ciencia no pudiera distinguir lo normal de lo patológico, la salud de la enfermedad, lo deseable de lo malo, perdería toda eficacia. Por el contrario, debe encontrar un criterio objetivo para tal distinción, de modo que pueda orientar el sentido de la práctica. Según la mirada durkheimiana, muy distinta en este punto a la weberiana, los problemas constituyen "patologías" que admiten "remedios" administrados por el "médico social" (el estadista, aconsejado por el científico social). El "médico social" reconoce la naturaleza moral de los problemas modernos y sabe qué reformas pueden aliviarlos. El estadista previene enfermedades mediante la higiene social, y si existen, procura curarlas (Durkheim, 1984).

Para el padre de la escuela francesa de Sociología, el conocimiento sociológico era un instrumento que puede ayudar a resolver problemas políticos y sociales, aunque sus soluciones a esos problemas no coinciden con las que formulan los partidos. Por eso se afirma que es más optimista que Weber respecto de las posibilidades/límites de la ciencia en relación a las orientaciones morales, políticas o de organización social.

Es necesario retomar la importancia que tiene para Durkheim el orden moral. De hecho, su gran y constante preocupación es el "debilitamiento de la moralidad común" y de la conciencia colectiva en el mundo moderno (de ahí la introducción del concepto de anomia). Desde su perspectiva, en la actualidad se corre el riesgo de que los individuos padezcan una pérdida patológica de los vínculos morales. Sin ellos, los individuos se dejan llevar por sus pasiones, por la búsqueda del placer (Durkheim, 2004). Resumiendo, Durkheim es ante todo un "moralista". Como dice Lukes (1984), la Sociología constituye el medio único de reconstruir la moral.

Por último, antes de pasar a analizar la perspectiva marxista, cabe señalar que esta valoración de la índole práctica de la ciencia social, no impide que Durkheim sea un cientificista, alguien que enfatiza el carácter científico de la Sociología y el deber de alcanzar conocimientos objetivos. En efecto, Durkheim intenta darle a la Sociología el status de una ciencia natural. La imagina como un saber objetivo, positivo; una ciencia en sentido estricto, que establece regularidades similares a las leyes de la naturaleza ${ }^{2}$. De ahí, su insistencia en señalar la diferencia esencial entre conocimiento científico y conocimiento vulgar; o en otras palabras, la ruptura entre la ciencia social y las prenociones, prejuicios tradicionales, opiniones arraigadas.

La "pretensión científica" es un rasgo común a los tres clásicos de la Sociología, y es tal vez lo que los diferencia de los "filósofos sociales", de los "precursores de la sociología" o "padres fundadores", que se valían en general de un fuerte componente normativo.

2 La tradición sociológica de raíz positivista, tanto en Francia como en Inglaterra, “...pretendía construir el conocimiento de lo social en base a un modelo objetivista, inspirado en las ciencias de la naturaleza" (Portantiero y De Ípola, 1987, p. 33). 
A continuación, se analiza la manera en que Marx piensa las relaciones que son objeto de esta reflexión. En el marxismo, si bien la práctica científica y la práctica política tienen cada una su especificidad, no hay una preocupación por excluir la política de la ciencia a la manera de Weber.

Incluso se podría decir que, al contrario de eso, Marx construye su teoría "tomando parte directamente" en las prácticas y luchas políticas del movimiento obrero. Marx y Engels actúan como "intelectuales orgánicos" de la clase obrera, representan en "economía política” el punto de vista del proletariado. La crítica de la economía política burguesa que se desarrolla en El capital -la obra científica de más largo aliento de Marx, si se quiere-, según dice Marx (1982) en el epílogo a la $2^{\circ}$ edición, representa a la clase que tiene por misión histórica trastocar el modo de producción capitalista y finalmente, abolir las clases: el proletariado. Lo que se desprende de esta idea es que Marx reconoce que escribe desde el punto de vista de una clase.

El pensamiento teórico de Marx se entrelaza con su pensamiento político y este con su práctica o lucha política. En efecto, el problema de la relación teoría marxista/movimiento obrero ha constituido todo un tema de debate entre quienes los estudian. Althusser, por ejemplo, en Marx dentro de sus límites, va a sostener la tesis de que "la teoría marxista no es exterior sino interior al movimiento obrero". El "cambio de base" del pensamiento de Marx — subraya Althusser - es producto de su participación personal en las luchas del movimiento obrero europeo de los años 40, de su encuentro con la experiencia de la explotación de la clase obrera en Inglaterra (caso de Engels) y con la lucha política de los socialistas y comunistas en Francia (caso de Marx) (Althusser, 2003).

Desde esta lectura (que claramente es una entre las muchas lecturas del marxismo), lejos de existir una autonomía de la posición en la ciencia (o teórica) en relación con la postura política, el pensamiento de Marx se ha formado $y$ desarrollado "en el interior" del movimiento obrero existente, $y$ no es algo que se produce fuera, en el ámbito científico, y se introduce a este movimiento desde el exterior, por intelectuales burgueses portadores de la ciencia. En el campo marxista, hay una unidad entre la teoría y la práctica, entre la teoría marxista y la lucha obrera, pensada bajo la forma de una primacía de la conciencia política de clase (motor del proceso) sobre la conciencia teórica.

Para terminar esta pequeña contrastación de las posturas de Marx y Weber respecto de la relación ciencia/política o de la relación entre posición teórica $y$ de clase, se menciona como ejemplo concreto el análisis que hacen ambos del trabajo industrial o del proceso de producción capitalista. En su análisis del modo de producción capitalista Marx escribe desde el punto de vista del proletariado y es consciente de ello; los textos de Weber sobre el trabajo industrial se sitúan deliberadamente en una posición "científica", "objetiva" y por ende "neutral".

Como se mencionó anteriormente, una de las críticas de Weber al marxismo ${ }^{3}$ es la concepción "normativa" de la historia. Desde el punto de vista weberiano, los marxistas toman posición, toman partido, o en su lenguaje, introducen sus "juicios de valor" en sus análisis. En cambio Weber pretende "imparcialidad" en los trabajos sobre la industria.

Entre 1908-1909, Max Weber participó de una investigación colectiva planeada por la Asociación de Política Social sobre Selección y Adaptación de los obreros en la gran industria. Esta iniciativa debe ser situada en el contexto de la preocupación habitual de su época por los problemas del industrialismo moderno, por las consecuencias de la expansión capitalista $y$ por la transformación de Alemania en un Estado industrial, preocupación que Weber compartía con el resto de los miembros de la Asociación y muchos de los representantes de la cultura alemana.

En su "Introducción metodológica para las encuestas de la 'Verein für Sozialpolitik' (Asociación de Política Social) sobre Selección y Adaptación de los obreros en las grandes fábricas", Weber (1994) escribe:

$3 \quad$ Para profundizar sobre los puntos nodales del diálogo de Weber con el materialismo histórico, cuyo tratamiento da cuenta de la condición irreductible de estos dos enfoques teóricos, véase Duek (2008). 
La 'Verein für Sozialpolitik' se sitúa, en esta encuesta, en el terreno de un objetivo exclusivamente científico... No se trata de cómo haya que 'juzgar' la situación social de la gran industria ni de si la situación en la que la gran industria coloca a los obreros es agradable o no, ni de si alguien tiene la 'culpa' de estos aspectos desagradables y quién sea ese alguien; se trata exclusivamente de establecer objetivamente hechos $y$ de indagar si tienen fundamento en las condiciones de existencia de la gran industria y en las características de sus obreros... La 'Verein' no piensa en que la encuesta suministre, por ejemplo, material para emitir un juicio 'moral' sobre los implicados, sean los empresarios o los obreros. Estos propósitos no servirían de ninguna manera a la neutralidad científica de esta investigación. Todo el problema de que aquí se trata es... un problema totalmente neutral desde el punto de vista de la política social... (pp. 27-28).

Se puede señalar, entonces, que en tanto para la teoría marxista, el concepto de productividad es inseparable del de lucha de clases, $y$ la cuestión de la duración de la jornada de trabajo y del salario no son cuestiones de productividad sino de lucha de clases. Para este autor, el problema del rendimiento laboral (la selección y la adaptación de los obreros) en las grandes fábricas es un problema totalmente neutral ${ }^{4}$.

Cabe mencionar que desde la consideración marxista, la perspectiva de la "rentabilidad", que propone Weber en sus trabajos de "sociología del trabajo industrial", no es "neutral", por el contrario, es la perspectiva de la clase interesada en la rentabilidad, es decir, la capitalista.

Si Weber aspira a la "neutralidad" o imparcialidad científica (y objetividad es, en su discurso, sinónimo de esas palabras), la teoría marxista o el materialismo histórico no cree

4 Para un examen pormenorizado de la perspectiva de Weber sobre el trabajo industrial y su contraposición con el enfoque marxista, se remite a Duek (2012). que tal neutralidad sea posible, en tanto no hay posición neutral desde donde ver el conflicto.

Contra toda la tradición positivista para la cual la condición de objetividad es "ocupar una posición nula, fuera del conflicto" (Althusser, 1978, p. 116), el investigador marxista debe “...ocupar posiciones teóricas (proletarias) de clase, antagónicas a toda posición teórica de clase burguesa, para poder constituir y desarrollar su ciencia" (Ibid, p. 115), esto es, para poder ver la explotación de clase que la ideología dominante necesita enmascarar. Según Althusser (1978), una sociedad de clases:

...en una realidad necesariamente conflictual, como lo es una sociedad de este tipo, no se puede ver todo desde todas partes, no se puede descubrir la esencia de esta realidad conflictual más que a condición de ocupar determinadas posiciones en el conflicto y no otras, puesto que ocupar pasivamente otras posiciones es dejarse arrastrar por la lógica de la ilusión de clase que se llama la ideología dominante (pp. 115-116).

Esta idea se encuentra presente en Lenin, para remontarse más atrás en la historia de la teoría marxista.

En una sociedad que tiene como base la lucha de clases no puede existir una ciencia social 'imparcial'. De uno otro modo, toda la ciencia oficial y liberal defiende la esclavitud asalariada, mientras que el marxismo ha declarado una guerra implacable a esa esclavitud. Esperar que la ciencia sea imparcial en una sociedad de esclavitud asalariada, sería la misma absurda ingenuidad que esperar imparcialidad por parte de los fabricantes en lo que se refiere al problema de si deben aumentarse los salarios de los obreros disminuyendo los beneficios del capital (Lenin, 1984, p. 19).

Por último, se aclara que este reconocimiento de la imposibilidad de la neutralidad en una ciencia conflictual no impide en el marxismo la pretensión de un conocimiento científico, 
se podría decir "objetivo", que diferencia a la ciencia de otros tipos de conocimiento. Objetividad y neutralidad no se usan acá indistintamente. En El capital, al tiempo que Marx admite que prima el punto de vista del proletariado, afirma el carácter científico del texto:

En economía política, la libre investigación científica tiene que luchar con enemigos que otras ciencias no conocen. El carácter especial de la materia investigada levanta contra ella las pasiones más violentas, más mezquinas y más repugnantes que anidan en el pecho humano: las furias del interés privado (1982, p. XV).

Marx finaliza el prólogo a la primera edición de su gran obra advirtiendo:

Acogeré con los brazos abiertos todos los juicios de la crítica científica. En cuanto a los prejuicios de la llamada opinión pública, a la que jamás he hecho concesiones, seguiré ateniéndome al lema del gran florentino: Segui il tuo corso, $e$ lascia dir le genti! ${ }^{5}$ (1982, p. XvI).

Se ha examinado sintéticamente a lo largo de estas páginas el tratamiento que los tres clásicos del marxismo hacen de la relación ciencia, moral y política. Si bien, Marx, Durkheim y Weber comparten una "pretensión científica", cada uno de ellos tiene una mirada específica de esas relaciones.

En síntesis y simplificando el examen de estas páginas, se considera que Durkheim es un defensor de la función práctica de la ciencia, en tanto es capaz de identificar los valores morales más adecuados para ciertas condiciones de una sociedad; Weber es un abanderado de la imparcialidad científica frente a valoraciones morales o políticas; $y$ en la teoría marxista existe un cuestionamiento a la idea de neutralidad, o lo que es lo mismo, un reconocimiento de una profunda imbricación entre pensamiento teórico y político.

5 "Sigue tu camino y deja que la gente hable".

\section{REFERENCIAS}

Althusser, L. (1978). Marx y Freud. Nuevos escritos. La crisis del movimiento comunista internacional frente a la teoría marxista. Barcelona: Editorial Laia.

Althusser, L. (2003). Marx dentro de sus limites. Madrid: Akal.

Aron, R. (1970). Las etapas del pensamiento sociológico. Buenos Aires: Editorial Siglo Xx.

Aron, R. (1998). Introducción a Weber, Max, El político y el científico. Madrid: Alianza Editorial.

Duek, C. (2008). Weber-Marx: avatares de un diálogo intelectual. Estudios avanzados, 10, 49-69.

Duek, C. (2012). El trabajo industrial en la perspectiva de Max Weber. Una confrontación con el enfoque marxista. Conflicto Social, 5 (7), 66-86.

Durkheim, E. (1984). Las reglas del método sociológico. Buenos Aires: Editorial La Pléyade.

Durkheim, E. (2004). La división del trabajo social. Buenos Aires: Ediciones Libertador.

Freund, J. (1986). Sociología de Max Weber. Barcelona: Ediciones Península.

Lenin, V. I. (1984). Tres fuentes y tres partes integrantes del marxismo. Buenos Aires: Editorial Anteo.

Lukes, S. (1984). Émile Durkheim. Su vida y su obra. Estudio histórico-crítico. Madrid: Siglo Xxi editores.

Marx, C. (1982). El capital. Crítica de la economía política. Tomo I. México: Fondo de Cultura Económica.

Parsons, T. (1968). La estructura de la acción social II. Madrid: Ediciones Guadarrama.

Portantiero, J. C. y De Ípola, E. (1987). Estado y Sociedad en el pensamiento clásico. Buenos Aires: Cántaro.

Rovira, J. (2004). Ciencia social y valores en Max Weber. Revista de Ciencias Sociales, 103-104, 127-142.

Weber, M. (1995). Biografía de Max Weber. México: Fondo de Cultura Económica.

Weber, M. (1983). "La ciencia como vocación". El trabajo intelectual como profesión. Barcelona: Editorial Bruguera. 
Weber, M. (1990a). El sentido de la 'neutralidad valorativa' de las ciencias sociológicas y económicas. Ensayos sobre metodología sociológica. Buenos Aires: Amorrortu Editores.

Weber, M. (1990b). Ensayos críticos sobre la lógica de las ciencias de la cultura. Ensayos sobre metodología sociológica. Buenos Aires: Amorrortu Editores.

Weber, M. (1990c). La 'objetividad' cognoscitiva de la ciencia social y de la política social. Ensayos sobre metodología sociológica. Buenos Aires: Amorrortu Editores.
Weber, M. (1994). Introducción metodológica para las encuestas de la 'Verein für Sozialpolitik' (Asociación de Política Social) sobre Selección y Adaptación de los obreros en las grandes fábricas. Sociología del trabajo industrial. Madrid: Editorial Trotta.

Fecha de ingreso: 10/01/2019 Fecha de aprobación: 05/02/2019 